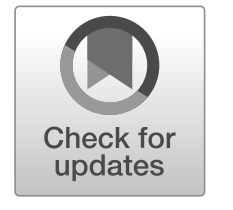

\title{
The influence of available comb storage space on the performance of honey bee communication signals that regulate foraging
}

\author{
Parry M. KIETZMAN ${ }^{1,2}$, P. Kirk VISSChER ${ }^{2}$ \\ ${ }^{1}$ Department of Entomology, Virginia Tech, Blacksburg, VA 24061, USA \\ ${ }^{2}$ Department of Entomology, University of California at Riverside, 900 University Ave., Riverside, CA 92521, USA
}

Received 2 December 2019 - Revised 16 July 2020 - Accepted 11 August 2020

\begin{abstract}
Numerous activities within honey bee (Apis mellifera L.) colonies rely on feedback loops for organization at the group level. Many of the processes associated with the feedback loops organizing a honey bee colony's activities are in striking parallel to other systems, such as intercellular interactions involved in motor neuron function, and principles derived from their study can be applied to these diverse fields, among others. This study looked at the communication signals honey bees employ while provisioning their nest with food to assess whether or not the bees use signals when their hive has no more available storage space. In this experiment, the storage space was alternated each day between no available space and ample space. The communication signals used by the bees were counted during each treatment and compared. When the hive had no storage space available, significantly more stop signals, which inhibit foraging, and tremble dances, which recruit more bees to unload incoming foragers, were observed. This suggests that the bees had noted the absence of storage space and were modifying their communication accordingly.
\end{abstract}

\section{Apis mellifera / behavior / communication / decision-making / foraging}

\section{INTRODUCTION}

In honey bees (Apis mellifera L.), the social recruitment behavior of foragers is driven by a network of excitatory and inhibitory communication signals (Seeley 1992, 1995; Kietzman and Visscher 2015). These include the waggle dance, tremble dance, and stop signal, which worker bees use to communicate with their nestmates while provisioning their nest with pollen and nectar collected from floral resources. These signals are delivered and received in concert by incoming foragers, prospective foragers, and the unloader bees

Corresponding author: P. Kietzman, parry@vt.eduM.

Kietzman, parry@vt.edu

Manuscript editor: James Nieh that take nectar from foragers and store it in the comb (Seeley 1992).

The well-documented waggle dance communicates the distance and direction to a food source and helps recruit foragers to that site (von Frisch 1967). During the waggle dance, the dancer runs across the surface of the comb in a figure-eight pattern (von Frisch 1967). She shakes her body in the center of the figure-eight, creating the "waggle run" component of the dance, where the angle of the waggle run relative to a $0^{\circ}$ vertical on a Cartesian plane communicates the direction of the food source relative to the sun's azimuth (von Frisch 1967). The duration of the waggle run is associated with the distance of the food source from the hive. The dance increases in number of waggle runs, duration, and dance tempo relative to increased quality food resources (Seeley et al. 
1991, 2000), which recruits more bees to follow the dances. The positive feedback generated from the waggle dance helps a colony flexibly allocate its foraging efforts across a heterogeneous environment (Donaldson-Matasci and Dornhaus 2012; Schürch and Grüter 2014). Higher quality food sources also elicit a higher wing beat frequency during the waggle dance than lower quality food sources (Lopuch and Tofilski 2020), and observable inter-individual differences in dance activity can be affected by social interactions between foragers (Schürch et al. 2016; George and Brockmann 2019).

Unlike pollen foragers, which search the combs in the hive and deposit their pollen loads in cells close to open brood cells (Dreller and Tarpy 2000), incoming nectar foragers are met by unloader bees, which take the nectar from the foragers and store it in open comb cells (Seeley 1992). If nectar foragers are not met quickly by unloader bees and instead experience a delay of approximately 50 or more seconds prior to unloading, they transition to producing the tremble dance (Seeley 1992, 1997). When a forager performs the tremble dance, which communicates that a rich nectar source has been found but the colony already has more incoming nectar than it can efficiently process, she recruits more individuals to be unloaders (Seeley 1992; Anderson and Ratnieks 1999; Biesmeijer 2003) and also causes a decrease in the recruitment of additional foragers (Seeley 1992; Kirchner 1993; Biesmeijer 2003). Similar to the waggle dance, the tremble dance acts as a signal and recruits follower bees to observe it (Seeley 1992; Lam et al. 2017). Through interaction with unloader bees, foragers indirectly gather information about their colony's nectar supply (Dreller et al. 1998).

The stop signal is a vibrational-acoustic communication signal produced when a bee presses her thorax to the wax comb and pulses her wings briefly (Michelsen et al. 1986) or butts her head into the side of another bee and pulses her wings (Nieh 1993). It has a fundamental frequency of $407 \mathrm{~Hz}$ and lasts $174 \pm 64 \mathrm{~ms}$ (Schlegel et al. 2012). The stop signal is best understood as a negative feedback signal that shuts down waggle dancing rapidly, and as a result, inhibits foraging (reviewed in Kietzman and Visscher 2015). In the context of foraging, the stop signal has been detected when an influx in food to the colony renders unloader bees unavailable to aid many of the incoming foragers, potentially due to the unavailability of storage space (Thom et al. 2003). In a different context, the stop signal is also used to alert nestmates to peril or overcrowding at a food source (Nieh 2010; Lau and Nieh 2010).

Signals such as the waggle dance, tremble dance, and stop signal are of key importance to bees as they forage for food because this is a cooperative act that involves thousands of individuals, each having only a small amount of information about the colony's nutritional needs and the locations of profitable food sources (Seeley 1997). Individuals in the colony must therefore continue to integrate and respond to information received from others in the colony. By using communication signals, individuals can influence other bees' decisions to forage or cease foraging, which over time can generate feedback loops and change the colony's behavior as a whole (reviewed in Bose et al. 2017). Compelling comparisons between self-organizing behaviors in social insect colonies including those of honey bees have been made within the realm of fields such as vertebrate neurobiology (reviewed in Marshall et al. 2009; Tremblay et al. 2017), swarm robotics (reviewed in Garnier 2011; Bose et al. 2017), and even computing systems (Babu et al. 2017).

The aim of this study was to investigate bees' response to changing amounts of storage space by assessing their levels of negative feedback signaling under different storage conditions. It would be advantageous to the bees if they were able to detect whether or not their hive has enough storage space available for incoming food, or conversely, if they could shut down foraging when space was not available. To test this idea, we measured the response of unloader bees to space availability by counting the number of stop signals, tremble dances, and waggle dances observed when their colony had no storage space available and compared it with when the colony was empty of food and had plenty of storage space available.

\section{METHODS}

\subsection{General methods}

This experiment was conducted from February through May 2014 at the University of California, 
Riverside $\left(33.9756^{\circ} \mathrm{N}, 117.3311^{\circ} \mathrm{W}\right)$. It was replicated three times using three different colonies of approximately 2000 workers each. Each queen-right colony was installed in a two-frame observation hive 3 to 4 days in advance of the start of data collection. The hives were housed in a shed at UC Riverside's research farm adjacent to the main campus.

The bees had access to the outside via a plastic tube entrance and were allowed to forage freely on naturally available food. A wooden shunt at the entrance of the hive directed incoming bees to a single side of the lower frame so that a single observer was able to see almost all of the of the waggle dances occurring inside the hive at any given time. The tight-fitting sides of the hive helped prevent incoming foragers from traveling to the other side of the frame to dance, though some movement from side to side was still possible. On the side viewed, the lower frame of the hive was covered by a wire mesh window screen so that stop signals could be heard. Prior to the start of data collection, the lower frame of the hive contained the brood nest area with a mix of eggs, developing larvae, capped brood, and some pollen and honey stores. During the days before the start of data collection, the upper frame was partially full of stored nectar and pollen. Data collection occurred from 7 to 12 February (colony 1), 7 to 12 March (colony 2), and 2 to 7 May (colony 3). These observational periods were logistically constrained by research assistant availability during the academic year but still chosen to fall within the timeframe of the bees' active foraging season in Southern California.

\subsection{Treatments}

At the start of the data collection period, the upper frame of the hive was replaced with one of two treatment frames on an alternating schedule. The frame for the "full comb" treatment was completely filled with stored honey and had no empty cells available for further food storage. Approximately $90 \%$ of the "full" treatment frame contained honey that had been previously stored and capped by bees. The remaining empty cells in the comb were filled with honey using a pipet prior to the frame's placement in the hive. The frame for the "empty comb" treatment had fully drawn wax comb but contained little or no stored food and therefore had ample space available for food storage.

For the duration of the experiment, the top frame in the hive was changed between the empty and full treatment frames each day. Each colony began with the empty treatment on the first day of data collection to maintain similar conditions across hives, and the frames were exchanged each evening after data collection was completed and the hive had finished foraging. For each colony, observations were made for 6 days, for a total of 3 days of each treatment per colony. A diagram of the experimental setup is found in Figure 1.

\subsection{Data collection}

Observations were made every half hour from 09:00 to 11:30 and from 12:30 to $16: 00$ for a total of twelve observations per day. During each observation, the number of waggle dances, tremble dances, and stop signals was counted during a 5min interval. During the 5 min immediately following this interval, the number of bees entering and exiting the colony was also counted to compare the bees' activity levels from day to day. The number of individual bees dancing and stop signaling was not counted; rather, the focus was on the number of dances and stop signals performed.

Waggle dances and tremble dances were observed by scan sampling the bees through visual inspection on the side of the lower frame that was covered by a screen. Scan sampling provided a tradeoff between efficiency of data collection and accuracy. Dances were counted in real time as they occurred, but because records were limited to observations made in a given moment, it is possible a small number of dancers were either missed or counted more than once. To mitigate this potential source of inaccuracy, only observers well-trained in dance observation (JL and AZ) counted dances. Stop signals were detected using a lapel microphone on a holder stick, as described by Schlegel et al. (2012), swept slowly across the front of the lower frame by an observer experienced in stop signal detection (PK). 


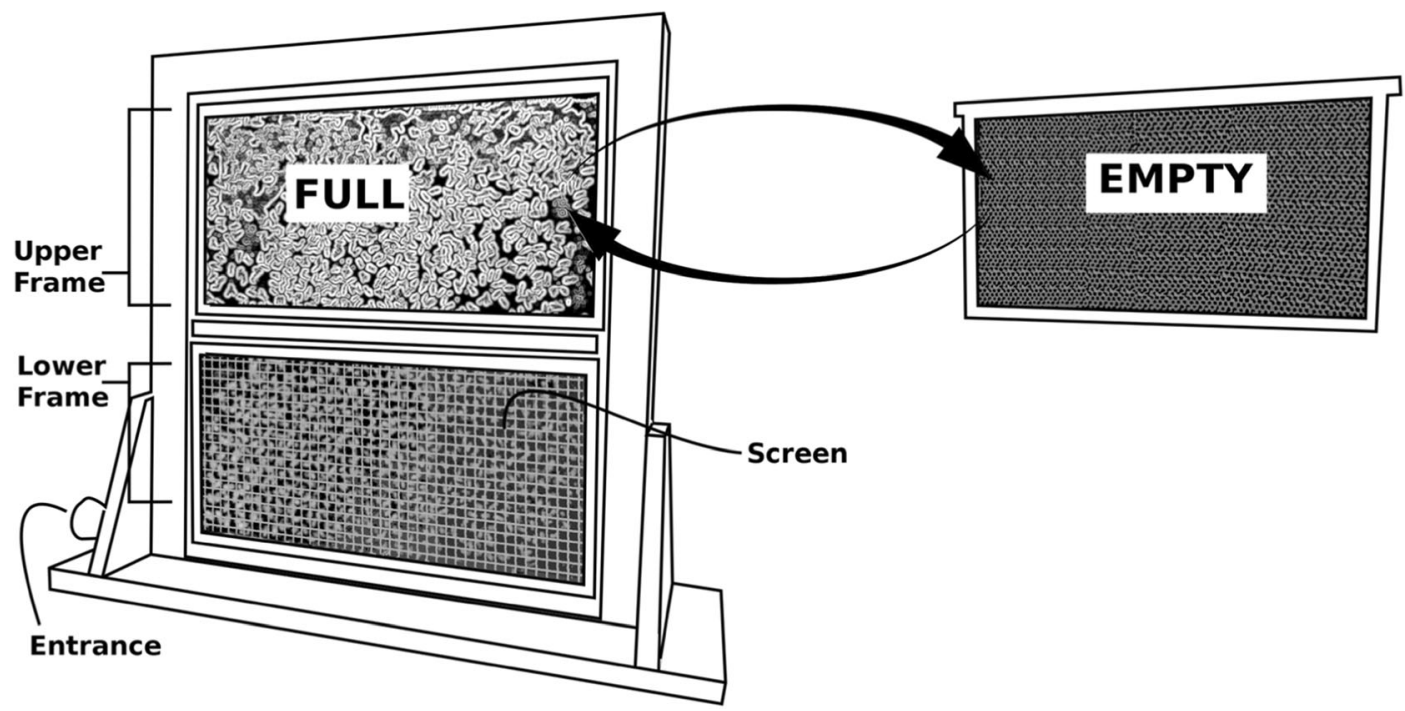

Figure 1. Experimental setup showing the two-frame observation hives used in this experiment and the rotation of the treatment frames between a frame that was full of stored food and a frame that was empty and had plenty of storage space.

\subsection{Statistical analysis}

The data were analyzed using RStudio version 0.98.501 for Macintosh OS X 10.7.5. The number of stop signals, waggle dances, and tremble dances per treatment and time of day was checked for normality of distribution of the residuals using the Shapiro-Wilkes test ( $p$ value $<0.02$ ). Because the data were not normally distributed, the nonparametric Kruskal-Wallis rank-sum test was used to assess differences in the numbers of signals used during each treatment.

\section{RESULTS}

Table I shows the total number of stop signals, waggle dances, and tremble dances observed during each treatment for all three colonies. We used non-parametric tests because none of the data was distributed normally ( $p<0.001$ for all communication signals and treatments). Significantly more stop signals were heard during the full treatment than during the empty treatment for each of the three colonies $(p<0.001$, Kruskal-Wallis ranksum test, for all colonies). Significantly more tremble dances were also observed during the full treatment than during the empty treatment for all three colonies $(p<0.001$, Kruskal-Wallis ranksum test, for all colonies). There was no consistent treatment effect on waggle dances among the three colonies $(p>0.013$, Kruskal-Wallis ranksum test, for all colonies).

Some variation in the numbers of stop signals, waggle dances, and tremble dances performed was observed across the three colonies. With the exception of stop signals during the full treatment and tremble dances during the empty treatment, all communication signals varied significantly when all three colonies were compared ( $p$ value $<0.01$, Kruskal-Wallis rank-sum test, for all signals). These findings are summarized in Table II part a. However, colony 3 had higher rates of stop signaling and waggle dancing than the other two colonies (Table I). When colonies 1 and 2 were compared with each other, they were not found to be significantly different (Kruskal-Wallis ranksum test, $p$ value $>0.05$ for all signals) except for waggle and tremble dances during the full treatment. These findings are summarized in Table II part $b$. The differences observed in the pattern of results across the three colonies can be attributed to individual variations among colonies; 
Table I. Summary of the total number of stop signals, waggle dances, and tremble dances observed during the full and empty treatments for each colony

Total number of stop signals, waggle dances, and tremble dances

\begin{tabular}{lllllllllll}
\hline Col. & Treatment & $\begin{array}{l}\text { \# of stop } \\
\text { signals }\end{array}$ & $X^{2}$ & $p$ value & $\begin{array}{l}\text { \# of waggle } \\
\text { dances }\end{array}$ & $X^{2}$ & $p$ value & $\begin{array}{l}\text { \# of tremble } \\
\text { dances }\end{array}$ & $X^{2}$ & $p$ value \\
\hline 1 & Full & 117 & 22.2 & $<0.001$ & 43 & 2.4 & 0.12 & 153 & 35.6 & $<0.001$ \\
& Empty & 39 & & & 62 & & & 27 & & \\
2 & Full & 140 & 27.3 & $<0.001$ & 19 & 6.1 & 0.013 & 125 & 40.1 & $<0.001$ \\
& Empty & 44 & & & 55 & & & 33 & & \\
3 & Full & 190 & 37.3 & $<0.001$ & 88 & 0.33 & 0.56 & 136 & 41.3 & $<0.001$ \\
& Empty & 59 & & & 99 & & & 32 & &
\end{tabular}

The results of the Kruskal-Wallis rank-sum test are also reported for each colony and communication signal

however, when analyzed individually, each showed comparable responses to the treatments (Table I).

The differences between the number of stop signals and tremble dances observed between the treatments are shown in Figure $2 \mathrm{a}$ and $\mathrm{b}$, which display the mean number of signals counted at each observational period for all three colonies. The number of stop signals and tremble dances was higher during the full treatment than during the empty treatment. The number of waggle dances showed less variation between treatments (Figure 2c).

All three colonies demonstrated entrance activity during the data collection periods, with the number of bees entering and exiting the hive varying broadly based on time of day. The number of bees entering the hives per 5-min interval

Table II. Results of Kruskal-Wallis rank-sum tests comparing the number of signals produced by all three colonies (a) and colonies 1 and 2 (b)

\begin{tabular}{llll}
\hline Communication signal & Treatment & $\mathrm{X}^{2}$ & $p$ value \\
\hline a & & & $<0.01$ \\
Stop & Empty & 14.762 & 0.067 \\
Stop & Full & 5.0411 & $<0.01$ \\
Waggle & Empty & 14.206 & $<0.01$ \\
Waggle & Full & 24.439 & 0.91 \\
Tremble & Empty & 0.18021 & $<0.01$ \\
Tremble & Full & 53.049 & \\
b & & & 0.61 \\
Stop & Empty & 0.2559 & 0.073 \\
Stop & Full & 3.2197 & 0.19 \\
Waggle & Empty & 1.7363 & $<0.001$ \\
Waggle & Full & 4.2084 & 0.76 \\
Tremble & Empty & 0.0913 & $<0.001$ \\
Tremble & Full & 38.399 & \\
\hline
\end{tabular}




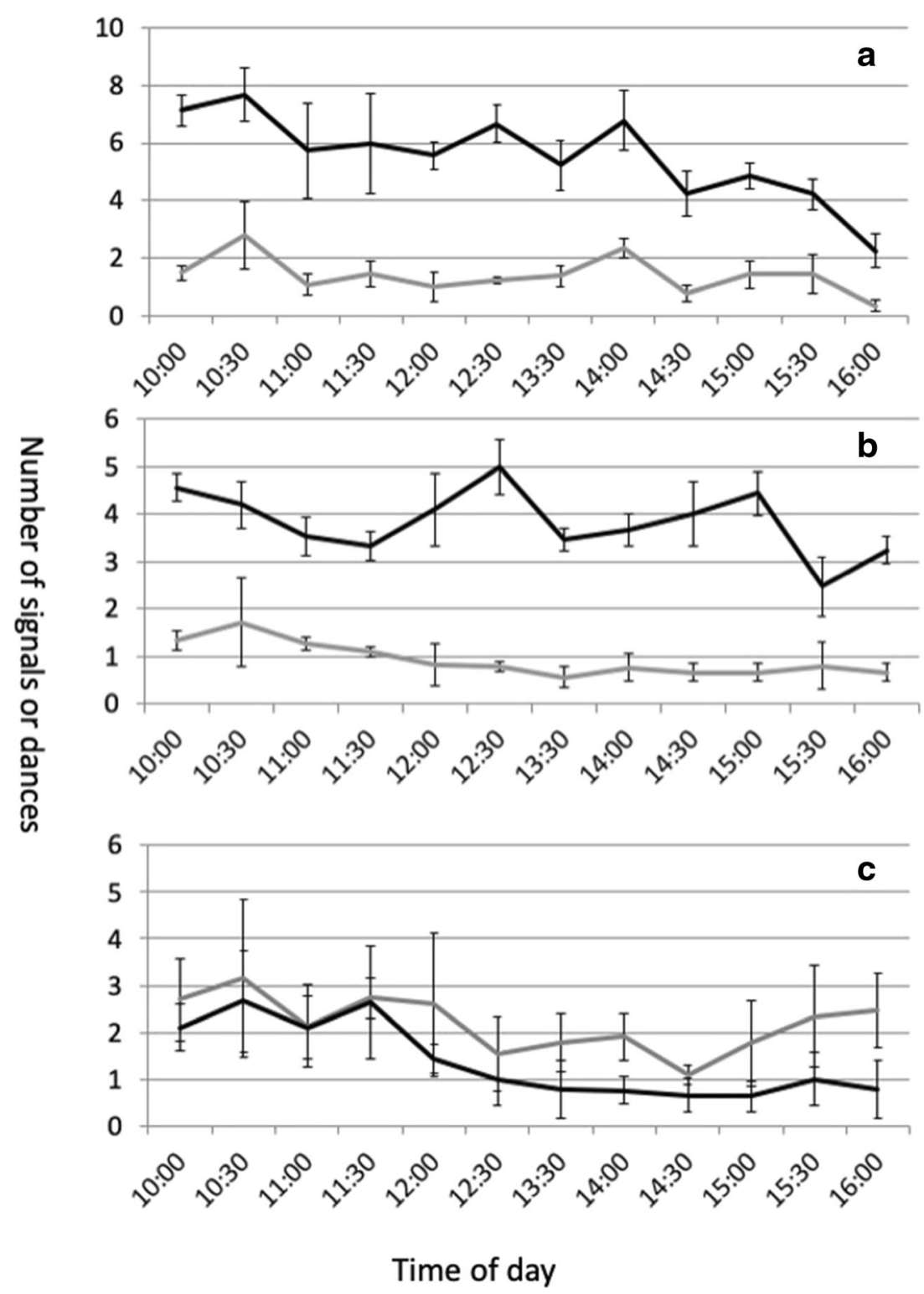

Figure 2 a a-c Signaling in all colonies during the full (black lines) and empty (gray lines) treatments at each of the 12 observational periods. The graphs display the number of a stop signals, $\mathbf{b}$ tremble dances, and $\mathbf{c}$ waggle dances observed at each observational period, averaged over all three colonies. Error bars display the standard error.

ranged from 4 during periods of low activity such as the morning or late afternoon to 442 during periods of peak activity (mean $=103.11, n=211$ ). The number of bees exiting the hives per 5-min interval ranged from 6 to 408 (mean $=103.00$, $n=211$ ).

\section{DISCUSSION}

Bees consistently used more stop signals and tremble dances during the full treatment than during the empty treatment, which suggests two alternatives. One is that perhaps the unloader bees 
were able to experience the lack of space, and being unable to store nectar, they had taken from foragers, could not unload further incoming foragers, and thus used the stop signal to inhibit further foraging. Alternatively, the foragers may have produced the stop signals because they were unable to be unloaded. Because we did not use age-controlled bees, we were not able to identify which individuals were producing the stop signals during this experiment; thus, a limitation of this study is that it is not possible to know if they were primarily unloader bees or foragers.

Both the tremble dance and the stop signal decrease waggle dancing in a colony (Seeley 1992; Kietzman and Visscher 2015), though this study did not find a decrease in waggle dancing when there was increased tremble dancing and stop signaling in the hive. This lack of effect was unexpected and is difficult to explain. It should be noted that this study was limited to counts of waggle dances, tremble dances, and stop signals, and as such other interactions between foragers and unloader bees were not examined. Other criteria that affect foraging decisions, such as the number of waggle runs, dance tempo (Seeley et al. 1991, 2000), and wing beat frequency (Łopuch and Tofilski 2020), were not measured.

Additionally, Thom et al. (2003) suggested that stop signaling by foragers might modulate the recruitment of more unloader bees by lowering their response thresholds to the tremble dance. The increase in tremble dancing during the full treatment may therefore have increased the colonies' nectar handling capacities and account for the similarities in the amount of waggle dancing between the treatments.

Communication signals employed by social insects that lead to positive and negative feedback loops are of increasing interest to scientists due to the robust decision-making processes they enable. In a social insect colony, each individual worker operates using a simple repertoire of behaviors; however, as a group, they can efficiently execute complex tasks such as regulating foraging or selecting a new nest site (reviewed in Visscher 2007). Negative feedback is used to modulate foraging responses in other social insect systems, such as ants (Grüter et al. 2012). Recruitment to food sources can be increased or decreased based on the amount of trail pheromone deposited (Beckers et al. 1993), and foraging ants have been shown to respond to overcrowding at food sources by depositing more trail pheromone to unoccupied sources (Wendt et al. 2020).

The results of this study present an exciting example of self-organizing behaviors within a social insect system. Each individual bee may play a single role; however, as a group, they succeed in the complex task of regulating their colony's food intake based on information available to a small percentage of individuals.

\section{ACKNOWLEDGMENTS}

The authors would like to thank Jacqueline Lalor and Anna Zakarian for their assistance in the field. They would also like to thank the two anonymous reviewers for their valued input.

\section{AUTHOR CONTRIBUTIONS}

PMK and PKV conceived and designed the experiment. PMK conducted the experiment. PMK and PKV collaborated on the analysis. PMK wrote the paper. All authors read and approved the final manuscript.

L'influence de l'espace disponible des rayons pour le stockage sur la performance des signaux de communication des abeilles qui régulent la recherche de nourriture.

Apis mellifera / comportement / communication / prise de décision / butinage.

Der Einfluss des verfügbaren Raums für Futtervorräte im Volk auf die Verbreitung von Kommunkationssignalen, die die Sammelaktivität bei Honigbienen regulieren.

\section{Apis mellifera / Verhalten / Kommunikation / Entscheidung / Sammeln.}

\section{REFERENCES}

Anderson, C., Ratnieks, F. (1999) Worker allocation in insect societies: coordination of nectar foragers and nectar receivers in honey bee (Apis mellifera) colonies. Behav Ecol Sociobiol 46, 73-81. 
Babu S., Sree Rathna Lakshmi N.V.S., Sivakumar B. (2017) An analysis of decision-making structure for self-organizing system based on software engineering. Computers and Electrical Engineering 57: 81-90.

Beckers R., Deneubourg J-L., Goss S. (1993) Modulation of trail laying in the ant Lasius niger (Hymenoptera: Formicidae) and its role in the collective selection of a food source. J Insect Behav 6: 751-759.

Biesmeijer J.C. (2003) The occurrence and context of tremble dancing in free-foraging honey bees. Behav Ecol Sociobiol 53: 411-416.

Bose T., Reina A., Marshall J. A. R. (2017) Collective decision-making. Curr Op Behav Sci 16: 30-34.

Donaldson-Matasci M.C., Dornhaus A. (2012) How habitat affects the benefits of communication in collectively foraging honey bees. Behav Ecol Sociobiol 66:583592.

Dreller C., Page R.E. Jr., Fondrk M. K. (1998) Regulation of pollen foraging in honeybee colonies: effect of young brood, stored pollen, and empty space. Behav Ecol Sociobiol 45: 227-233.

Dreller C., Tarpy D.R. (2000) Perception of the pollen need by foragers in a honeybee colony. Animal Behaviour 59: 91-96.

von Frisch K. (1967) The Dance Language and Orientation of Bees. Transl. by L. E. Chadwick. Cambridge, MA: Harvard University Press.

Garnier S. (2011) From Ants to Robots and Back: How Robotics Can Contribute to the Study of Collective Animal Behavior. In: Meng Y., Jin Y. (eds) BioInspired Self-Organizing Robotic Systems. Studies in Computational Intelligence, vol 355. Springer, Berlin.

George E.A., Brockmann A. (2019). Social modulation of individual differences in dance communication in honey bees. Behav Ecol Sociobiol 73: 41.

Grüter C., Schürch R., Czaczkes T. J., Taylor K., Durance T., Jones S. M., et al. (2012) Negative feedback enables fast and flexible collective decision-making in ants. PLoS ONE 7:e44501.

Kietzman P.M., Visscher P.K. (2015) The anti-waggle dance: use of the stop signal as negative feedback. Front Ecol Evol 3: 1-5.

Kirchner W.H. (1993) Vibrational signals in the tremble dance of the honey bee, Apis mellifera. Behav Ecol Sociobiol 35:303-308.

Lam C., Li Y., Landgraf T., Nieh J. (2017). Dancing attraction: followers of honey bee tremble and waggle dances exhibit similar behaviors. Biology Open 6:810-817.

Lau C., Nieh, J. (2010) Honey bee stop-signal production: temporal distribution and effect of feeder crowding. Apidologie 41: 87-95.

Łopuch, S., Tofilski, A. (2020) Impact of the quality of food sources on the wing beating of honey bee dancers. Apidologie. https://doi.org/10.1007/s13592-020-00748-3

Marshall J.A., Bogacz R., Dornhaus A., Planque R., Kovacs T., Franks N.R. (2009) On optimal decision- making in brains and social insect colonies. J. R. Soc. Interface 6: 1065-1074.

Michelsen A., Kirchner W., Lindauer M. (1986) Sound and vibrational signals in the dance language of the honey bee, Apis mellifera. Behav. Ecol. Sociobiol. 18: 207212.

Nieh J. (1993) The stop signal of the honey bee: reconsidering its message. Behav Ecol Sociobiol 33: 51-56.

Nieh J. (2010) A negative feedback signal that is triggered by peril curbs honey bee recruitment. Curr Biol 20: 310-315.

Schlegel T., Visscher P.K., Seeley T.D. (2012) Beeping and piping: characterization of two mechano-acoustic signals used by honey bees in swarming. Naturwissenschaften 99: 1067-1071.

Schürch R., Grüter C. (2014). Dancing bees improve colony foraging success as long-term benefits outweigh short-term costs. PLoS One 9:e104660.

Schürch R., Ratnieks F.L.W., Samuelson E.E.W.W., Couvillon M.J. (2016). Dancing to her own beat: honey bee foragers communicate via individually calibrated waggle dances. J Exp Biol 219:1287-1289.

Seeley T.D. (1992) The tremble dance of the honey bee: messages and meanings. Behav Ecol Sociobiol 31: 375-383.

Seeley T.D. (1995) The Wisdom of the Hive. Massachusetts: Harvard University Press.

Seeley T.D. (1997) Honey bee colonies are group level adaptive units. Am Nat 150: 22-41.

Seeley T.D., Camazine S., Sneyd J. (1991) Collective decision-making in honey bees: how colonies choose among nectar sources. Behav Ecol Sociobiol 28: 277-290.

Seeley T.D., Mikheyev A.S., Pagano G.J. (2000) Dancing honey bees tune both duration and rate of waggle-run production in relation to nectar-source profitability. $\mathrm{J}$ Comp Physio.A 186: 813-819.

Thom C., Gilley D., Tautz J. (2003) Worker piping in honey bees (Apis mellifera): the behavior or piping nectar foragers. Behav Ecol Sociobiol 53: 199-205.

Tremblay S., Sharika K.M., Platt L.M. (2017) Social decision-making and the brain: a comparative perspective. Trends Cog Sci 21: 265-276.

Visscher P.K. (2007) Group decision making in nestsite selection among social insects. Annu Rev Entomol 52: 255-275.

Wendt S., Kleinhoelting N., Czaczkes T.J. (2020) Negative feedback: ants choose unoccupied over occupied food sources and lay more pheromone to them. J R Soc Interface 17: 20190661.

Publisher's note Springer Nature remains neutral with regard to jurisdictional claims in published maps and institutional affiliations. 